\title{
(TRANS)FORMACIONES, METAMORFOSIS Y MUNDOS HÍBRIDOS: VARIACIONES SOBRE LO FANTÁSTICO
}

\author{
Magdolna Orosz \\ Universidad Eötvös Loránd, Budapest \\ orosz.magdolna@btk.elte.hu
}

Resumen: La literatura fantástica ha sido investigada desde diversos puntos de vista: lo fantástico puede ser considerado como género y también como una particular estructura textual ambivalente que cuenta con elementos temáticos y motívicos específicos. La crítica literaria que se ocupa del complejo fenómeno de lo fantástico asimismo enfoca sus aspectos históricos, por ejemplo, la cuestión concerniente a la desaparición de lo fantástico en el siglo XX o a su persistencia en formas modificadas. Después de revisar una serie de diversas aproximaciones teóricas hacia lo fantástico y su "renacimiento" en lo neo-fantástico, el presente estudio propone ejemplos temáticamente vinculados con las modificaciones de la narrativa tanto fantástica como neo-fantástica de las literaturas húngara, alemana y catalana, de su construcción intertextual y metafórica, demostrando las diferencias, pero también los aspectos comunes de fantástico en sus variadas formas estructurales e históricas.

Palabras clave: teoría de lo fantástico, neo-fantástico, variaciones históricas y estructurales de lo fantástico, Viktor Cholnoky, Leo Perutz, Franz Kafka, Quim Monzó

\begin{abstract}
Fantastic literature has been investigated from different points of view: the fantastic can be considered as a genre or as a specific ambivalent text structure with specific thematic and motivic elements. Literary criticism dealing with the complex phenomenon of the fantastic focuses also on its historical aspects, i.e. on the question whether the fantastic disappears in 20th century or it persists in some modified forms. After a review of some divergent theoretic approaches to the fantastic and to its ,rebirth" in the neo-fantastic, the paper brings some thematically related examples of Hungarian, German and Spanish literature for the modifications of the fantastic as well as the neo-fantastic narratives, for their intertextual and metaphorical construction, demonstrating the differences but also the common features of the fantastic in its various structural and historical forms.
\end{abstract}

Keywords: theories of the fantastic, neo-fantastic, historical and structural variations of the fantastic, Viktor Cholnoky, Leo Perutz, Franz Kafka, Quim Monzó

DOI: https://doi.org/10.24029/lejana.2017.10.164

Recibido: el 13 de julio de 2017

Aceptado: el 9 de septiembre de 2017

Publicado: el 4 de noviembre de 2017 


\section{Lo fantástico y la literatura fantástica: acercamientos teóricos}

La cuestión y la naturaleza de lo fantástico han sido objetos de largas discusiones en la historia literaria, cultural y en las ciencias culturales, y siguen siéndolo hasta hoy; en estas, se presta una atención particular a las fuentes de lo fantástico, a sus géneros representativos, a sus distintas formas, variaciones y transformaciones, que tienden a materializarse y sufrir cambios substanciales según contextos históricos y sociales. El libro representativo de Tzvetan Todorov, Introducción a la literatura fantástica, publicado en 1970, no ha hecho otra cosa que continuar una serie de discusiones de más de un siglo y medio para conducir a categorías más exactas. Según Todorov, “[1]a expresión «literatura fantástica» se refiere [...] a un género literario" (1981: 3), y después de categorizarla como género, procede a describir sus propiedades según rasgos estructurales. En concreto, Todorov indica la incertidumbre y la ambivalencia como bases del género, opinando que lo fantástico es la "experiencia de los límites" (1981: 36), la vacilación entre la explicación "real" e "irreal" de los acontecimientos narrados, y la raíz de la explicación que se vuelve incierta por la vacilación misma, por tanto, “[1]o fantástico es la vacilación experimentada por un ser que no conoce más que las leyes naturales, frente a un acontecimiento aparentemente sobrenatural" (1981: 19). La contradicción, la incertidumbre y la ambigüedad insolubles del mundo narrado "real" e "irreal" provocan el momento decisivo: la percepción y la recepción se vuelven inciertas dentro del texto, las cuales constituirán el criterio principal de "lo fantástico", y es precisamente esta contradicción y la incertidumbre mantenida la que separa "lo fantástico" de la categoría de "lo maravilloso" y de "lo extraño", así como de sus modulaciones.

Para Todorov lo fantástico tiene una interpretación bastante estrecha, su definición como género presenta problemas, y los textos aducidos como ejemplos no siempre cumplen sus propias restricciones. A diferencia de Todorov - y, en parte, ya antes de él- Roger Caillois y Louis Vax parten de características del contenido y de la estructura: consideran que los rasgos principales del relato fantástico son ciertos elementos temáticos y la contradicción entre el mundo real, comprensible, y el otro, irreal e incomprensible. ${ }^{1}$ Vax subraya que lo fantástico conlleva la ambivalencia y la ambigüedad, pero él procede a dividirla en tres formas: "la ambigüedad psicológica o afectiva, la epistémica y la ontológica" (Vax, 1992: $33),{ }^{2}$ permitiendo así una visión más diferenciada.

Con base en las consideraciones anteriores y en parte precisándolas, desarrollándolas y concentrándose en fenómenos estructurales, Marianne Wünsch no restringe lo fantástico a los textos literarios, sino que lo usa en referencia a dramas, películas, etc., independientemente del medio, y así — a diferencia de Todorov— no lo define como género, sino como estructura con sus propias regularidades. Según ella, un texto de este tipo "crea un mundo compatible con el concepto de realidad vigente; pero en este mundo aparecen fenómenos (figuras y

\footnotetext{
${ }^{1}$ Según Caillois "Todo lo fantástico es una ruptura del orden reconocido, una irrupción de lo inadmisible en la inalterable legalidad cotidiana" [Tout le fantastique est rupture de l'ordre reconnu, irruption de l'inadmissible au sein de l'inaltérable légalité quotidienne] (Caillois, 1965: 61); Vax opina que "el relato fantástico [...] quiere presentarnos, a los habitantes de nuestro mundo real donde vivimos, a hombres como nosotros, situados súbitamente en presencia de lo inexplicable" [Le récit fantastique [...] aime nous présenter, habitant le monde réel où nous sommes, des hommes comme nous, placés soudainement en présence de l'inexplicable] (Vax, 1960: 5).

${ }^{2}$ Donde no exista la versión española del texto, las traducciones siempre serán de Ádám András Kürthy. (Nota del traductor)
} 
acontecimientos) que son, no obstante, incompatibles con este mismo concepto" (Wünsch, 2000: 175), y luego afirma:

[...] estos fenómenos imposibles se suponen reales en el mundo figurado, por tanto, necesitan una explicación. El texto puede ofrecer una explicación del fenómeno misterioso o, al contrario, rechazar la explicación. Si esta se sirve, será compatible con el saber cultural [...] o la explicación remite a "saberes" culturalmente no dominantes, distintos — por ejemplo, ocultistas-, con lo cual mantiene la suposición de lo inexplicable como algo real. Por fin, el texto puede ofrecer una explicación racional y otra oculta a la vez, y conservar así el estado ambivalente del fenómeno en la realidad. (Wünsch, 2000: 175)

La variabilidad de las explicaciones del fenómeno de lo fantástico perdura hasta hoy; estas pueden agruparse, por una parte, según su definición de lo fantástico como género o con base en rasgos estructurales; por otra, según sus diferencias en el acercamiento a su objeto: usando una restricción rigurosa, o describiendo tan solo algunos rasgos generales: una vertiente puede llamarse "maximalista", y la otra, "minimalista", siguiendo a Uwe Durst. ${ }^{3}$ Según Durst, a la concepción maximalista "pertenecen todos los textos narrativos en los que las leyes de la naturaleza se quiebran" (Durst, 2001: 27), pero "la duda ante la facticidad de lo sobrenatural en la ficción no juega un papel definitorio" (Durst, 2001, 36), o sea, la duda y la incertidumbre, requeridas por Todorov, no tienen importancia. En cambio, según la concepción minimalista aceptada por el mismo Durst, el criterio decisivo es la incertidumbre frente a la existencia o inexistencia de lo sobrenatural intratextual y, por consiguiente, el círculo de los textos fantásticos queda restringido (Durst, 2001: 36sigs.). Las categorías colindantes se definen según si la interpretación es más amplia o más restringida: lo maravilloso y lo extraño, o incluso fenómenos como la utopía o la ciencia ficción. Sin embargo, muchos discuten el acercamiento minimalista de Durst, ya que así continúa la interpretación desproporcionadamente restringida de Todorov, sin disolver sus contradicciones del todo.

La proyección histórica de lo fantástico también es una cuestión significante: si se trata de una categoría atemporal o se relaciona con ciertas épocas y períodos. Todorov aboga por la segunda opción al explicar que "la literatura fantástica no es más que la conciencia intranquila de ese siglo XIX positivista" (1981: 122), y por ende lo considera como una reacción contraria a la visión ilustrada y racional del mundo, que "[a]pareció de manera sistemática con Cazotte, hacia fines del siglo XVIII; un siglo después, los relatos de Maupassant representan los últimos ejemplos estéticamente satisfactorios del género" (1981: 120). Todorov explica que la desaparición de lo fantástico se produjo por la aparición de la teoría de Freud, ya que, en su criterio, "el psicoanálisis reemplazó (y por ello mismo volvió inútil) la literatura fantástica” (1981: 116). Al contrario de esta opinión, se formula también la teoría de la persisitencia de lo fantástico, según la cual lo fantástico no desaparece en el siglo $\mathrm{XX}$, sino sigue existiendo hasta nuestros días, revistiendo, sin embargo, formas distintas. Entre otros, Peter Cersowsky dedicó una monografía exhaustiva a las transformaciones de lo fantástico a comienzos del siglo XX, concentrándose en tres autores privilegiados (Meyrink, Kubin, Kafka), de los cuales Kafka es la fuente de la renovación de lo fantástico. No es casual que la extensa monografía de Marianne Wünsch sobre la literatura fantástica en lengua

\footnotetext{
${ }^{3}$ Uwe Durst usa este método en su monografía sobre las teorías de lo fantástico (Durst, 2001: 27-42), pero al mismo tiempo logra presentar las propuestas intermedias.
} 
alemana de entre 1880 y 1930 se detenga en numerosos autores que representan distintas ramas de lo fantástico en la época examinada. ${ }^{4}$ En Wünsch aparecen, sobre todo, variaciones sobre las influencias del ocultismo en la época, que pueden considerarse como respuesta a los descubrimientos científicos y técnicos que se presentan desde finales del siglo XIX, con una base optimista en la filosofía positivista, que supone la posibilidad de conocer el mundo y el Yo. Llama la atención el apogeo de la ciencia ficción como género literario: basta con pensar en la popularidad, el renombre continental y la influencia de las obras de Jules Verne (Innerhofer, 1996: 77-84). Sin embargo, los avances de la ciencia y la técnica, junto con la influencia que ejercen sobre la calidad de vida pronto despiertan dudas: plantean la sujeción del ser humano ante las fuerzas impenetrables y los peligros de la automatización. Los movimientos ideológicos contrastantes se observan de manera patente en la popularidad del ocultismo y fenómenos afines a partir de finales del siglo XIX, en el cual - tal como lo demuestran tanto Wünsch como Titzmann (2002: 183sigs.) - el ocultismo (sin llegar a ser discurso dominante) se plantea como competidor del discurso científico, y su ideario debido justamente a la presencia de elementos fantásticos - aparece en buena parte de la literatura de la época. ${ }^{5}$

El planteamiento del fenómeno de "lo neo-fantástico" puede considerarse un momento importante de renovación conceptual en la investigación histórica y teórica postodoroviana ${ }^{6}$ de lo fantástico, que se va perfilando con base en obras representativas de la literatura latinoamericana —Borges, Cortázar, Márquez- (véase Barbetta, 2006). Sin embargo, varios estudios coinciden en que puede servir para explicar incluso el peculiar mundo narrativo de Kafka. La exploración del fenómeno de lo neo-fantástico aparece en un libro de Jaime Alazraki, publicado en 1983 sobre Julio Cortázar: ${ }^{7}$ en él, Alazraki declara que los textos de Cortázar representan "un nuevo tipo de ficción en busca de su género" (1990: 26), y así atribuye la formación de lo neo-fantástico al mismo Kafka. Estos textos son "[n]eofantásticos porque a pesar de pivotear alrededor de un elemento fantástico, estos relatos se diferencian de sus abuelos de siglo XIX por su visión, intención y su modus operandi” (1990: 28). En cuanto al aspecto de la "visión”, "lo neofantástico asume el mundo real como una máscara, como un tapujo que oculta una segunda realidad" (1990: 29), y en su intención se difieren de los textos fantásticos, ya que el miedo que caracteriza estos últimos "no se da en el cuento neofantástico" (1990: 29), en cambio, obtienen un sentido metafórico. ${ }^{8}$ El modus operandi consiste en que "[d]esde las primeras frases del relato, el cuento neofantástico nos introduce, a boca de jarro, al elemento fantástico: sin progresión gradual, sin utilería, sin pathos” (1990:

\footnotetext{
${ }^{4}$ También se ocupan de lo fantástico del siglo XX los estudios en: Bauer, Gerhard/Stockhammer, Robert (ed.): Möglichkeitssinn. Phantasie und Phantastik in der Erzählliteratur des 20. Jahrhunderts. Wiesbaden: Westdeutscher Verlag, 2000.

${ }^{5}$ Clemens Ruthner ofrece un inventario sobre la literatura fantástica alemana y austríaca de la temprana modernidad, resaltando su relación con los discursos esotéricos de la época; véase Ruthner, Clemens: "Jenseits der Moderne. Abriß und Problemgeschichte der deutschsprachigen Phantastik 1890-1930". En: Thomas Le Blanc / Bettina Twrsnick (eds.): Traumreich und Nachtseite. Die deutschsprachige Phantastik zwischen Décadence und Faschismus. Wetzlar: Förderkreis Phantastik, 1995. 65-85.

${ }^{6}$ Para ver la teoría "postodoroviana” de lo fantástico, consúltese Ruthner, Clemens / Reber, Ursula / May, Markus (eds.): Nach Todorov. Beiträge zu einer Definition des Phantastischen in der Literatur. Tübingen: Francke, 2006.

${ }^{7}$ Alazraki, Jaime: En busca del unicornio: Los cuentos de Julio Cortázar. Madrid: Gredos, 1983.

8 “También en los cuentos de Cortázar el elemento fantástico [...] [es] portador [...] de un sentido metafórico" (Alazraki, 1990: 29).
} 
31). Según Alazraki, lo neo-fantástico se origina justo en donde Todorov supone el final de la literatura fantástica, encontrando así la solución para el problema de la continuidad histórica. Lo fantástico no se pierde, se transforma: "el relato neofantástico está apuntalado por los efectos de la primera guerra mundial, por los movimientos de vanguardia, por Freud y el psicoanálisis, por el surrealismo y el existencialismo, entre otros factores” (1990: 31).

Matias Martínez también se refiere a Kafka a la hora de reflexionar sobre la literatura fantástica moderna y, definiendo el concepto de lo neo-fantástico, se apoya parcialmente en las categorías de Wünsch, refinándolas un poco: mientras que en las obras de la literatura fantástica se suponen mundos heterogéneos, compatibles e incompatibles (ficticios) con la realidad, que son inestables (y regidos, por tanto, por la incertidumbre y la duda todorovianas), en los textos neo-fantásticos aparecen también mundos heterogéneos, siendo, en cambio, estos últimos estables, o sea, la exclusividad mutua de los mundos compatible e incompatible con la realidad no causa problemas, "rupturas", epistemológicas u ontológicas (Martínez, 2002: 124sigs.), sino aparece como natural para los personajes del mundo narrado, como queda ejemplificado en La metamorfosis de Kafka. ${ }^{9}$ El rasgo distintivo de lo neofantástico moderno/posmoderno poskafkiano será la transposición del énfasis desde el plano temático hacia el plano lingüístico, ya que estos textos "parten de una diferente concepción de la realidad. Aunque en el período temprano de lo neo-fantástico se tematiza la descomposición de la realidad cierta, más tarde, a partir de los 70, se destaca más el aspecto mediático — lingüístico e (inter)textual— de los textos" (Barbetta, 2006: 220). ${ }^{10}$

\section{Encuentros (neo-)fantásticos}

En la literatura finisecular del modernismo clásico se observan cambios múltiples: en los distintos discursos culturales se cristaliza una concepción del individuo que lo "postula como la totalidad de las posibilidades que encierra, las cuales se realizan solo de manera parcial en cualquier momento dado" (Titzmann, 1989: 36), y esta concepción incide profundamente en los rasgos de las obras literarias, ofreciendo a menudo la explicación de las metamorfosis del relato. Los cambios se presentan mayoritariamente en la problematización de los diferentes planos y elementos del texto narrativo: la heterogeneidad exterior e interior del individuo, su autorreflexividad y la intransparencia de sus sistemas de relaciones conducen a la postulación de la reflexión y de la imposibilidad parcial de la figura y de la narración. La cuestión de la narrabilidad aparece en muchas obras de la época, por ejemplo, en Los cuadernos de Malte Laurids Brigge de Rilke, donde la frase recurrente "aprender a ver" intenta organizar las experiencias visuales, las imágenes de la memoria y los fragmentos de lectura, o bien en $E l$ hombre sin atributos, gran novela ensayística de Robert Musil, en la que, a partir de las meditaciones de Ulrich, se desprende que la complicada red de interrelaciones en la que se ha

\footnotetext{
${ }^{9}$ Sophie von Glinski resume sucintamente los debates relativos a las propiedades de lo fantástico kafkiano, concentrándose sobre todo en La metamorfosis: Glinski, Sophie von: Imaginationsprozesse. Verfahren phantastischen Erzählens in Franz Kafkas Frühwerk. Berlin / New York: de Gruyter, 2004. 7-14. A propósito de la interpretabilidad de Kafka como narrador fantástico, véase Nix, 2005.

${ }^{10}$ En cuanto a lo fantástico posmoderno, véase Barbetta: Poetik des Neo-Phantastischen. Patrick Süskinds Roman "Das Parfum”. Würzburg: Königshausen \& Neumann, 2002. Alazraki también subraya la "literariedad", el carácter textual de los textos neo-fantásticos a propósito de Cortázar y Borges: "el cuento fantástico se mueve en el plano de la literalidad" (1990: 31).
} 
convertido el mundo ha imposibilitado el relato "simple", basado en la causalidad y en la ordenación cronológica (Musil, 1977: 910sigs.).

La obviedad de la narración, la posibilidad de la determinación causal del relato se ve problematizada en la mayoría de la cuentística del período, y la narración (tal como la literatura en general) empieza a verse determinada por "el uso no propio del lenguaje" y por una "autonomía no-mimética" (Titzman, 1989: 51): ${ }^{11}$ esto conlleva (entre otras consecuencias) una fuerte metaforización, en cuanto el relato narrado se vuelve metafórico, o se convierte en "metáfora narrada" mediante la explotación esmerada de las posibilidades del lenguaje y los juegos lingüísticos, demostrando así la cualidad metafórica ineludible del lenguaje propuesta por Nietzsche y, a la vez, sobrepasándola en la creación literaria (aunque Nietzsche mismo también concede esta posibilidad al arte: es solo el obstáculo de la cualidad metafórica en la cognición el que considera absoluto). ${ }^{12}$

La problemática del lenguaje, la reflexión sobre la cualidad metafórica del uso del lenguaje y su carácter inagotable ha llevado a algunos autores de la modernidad temprana a la formulación lúdica de las capacidades del lenguaje en sus funciones de moldear la identidad, o bien a la demonstración de las trampas y de la accidentalidad de la comunicación. ${ }^{13} \mathrm{El}$ énfasis sobre lo lingüístico puede funcionar como salida de la crisis del relato: tales obras "no se concentran en la historia sino enfatizan su carácter textual" (Thomka, 2001: 12). Es posible, sin embargo, otra solución, que desde la problemática de la imposibilidad de la narración conduce hacia lo fantástico: Marianne Wünsch, por una parte, constata que "en la literatura no fantástica de la época [...] los problemas del sujeto referidos a sí mismo [...] pueden aparecer necesariamente solo en el habla no propia, trópica [...]" (2000: 169), es decir, se descompone la historia narrada. Por otra parte, supone que la historia narrada se conserva en la literatura fantástica, ya que lo fantástico es capaz de "sustituir" lo metafórico, o sea, "la literatura fantástica de la época se realiza en el nivel de la «histoire» [...]: lo que en la literatura no fantástica es modalidad impropia del uso del lenguaje, y por consiguiente, no realidad, es lo que la literatura fantástica toma por su palabra y lo presenta como realidad" (1989: 169). ${ }^{14}$ Según esto, la literatura fantástica recupera la "historia" como base de su realidad ficticia postulada, y evade el dilema de su imposibilidad.

Sin embargo, el problema es más complejo, dado que la relación entre lo fantástico y lo metafórico tiene más capas en la modernidad de las que supone Wünsch, y en algunos casos es caracterizada por la relación entre "lo uno y lo otro". De ahí que sea posible la conjunción de una historia fantástica narrada con elementos metafóricos, y que la historia fantástica pueda corresponderse a una metáfora narrada. En lo siguiente, mencionaré algunos ejemplos de este fantástico metafórico, los cuales, al mismo tiempo, ponen de relieve lo fantástico finisecular en transformación, su transición hacia lo neo-fantástico y el posible

\footnotetext{
${ }^{11}$ Los fenómenos diagnosticados por Titzmann quedan expuestos en obras de otros estudiosos, aunque con una terminología dispersa (la cuestión queda fuera del alcance de este estudio).

${ }^{12}$ Cfr. el ensayo de Nietzsche Sobre verdad y mentira en sentido extramoral. A propósito de la concepción de la metáfora de Nietzsche, y especialmente sobre sus alusiones filosóficas y literarias, cfr. Árpád Bernáth: "Über Nietzsches Begriff der Metapher in seinem Essay Ueber Wahrheit und Lüge im aussermoralischen Sinne”. En su libro: Sprachliche Kunstwerke als Repräsentationen von möglichen Welten. Szeged: Grimm, 2004. 41-70.

${ }^{13}$ En este respecto, se encuentran numerosos ejemplos en las obras de Joseph Roth, Arthur Schnitzler, Leo Perutz, Viktor Cholnoky y otros. Para ello, consúltese Orosz, Magdolna: Erzählen - Identität - Erinnerung. Studien zur deutschsprachigen und ungarischen Literatur 1890-1930. Frankfurt/M.: Peter Lang, 2016.

${ }^{14}$ Es preciso aclarar que en este caso la "realidad" siempre significa la realidad ficticia, narrada.
} 
juego entre los dos mediante el motivo recurrente de una metamorfosis peculiar y sus conexiones intertextuales.

\subsection{La metáfora fantástica en Viktor Cholnoky}

En la literatura húngara finisecular también se descubren relaciones entre lo metafórico y lo fantástico en la obra de Viktor Cholnoky. En sus cuentos se conserva parcialmente la anécdota, pero los rasgos peculiares de su manera de narrar señalan la problemática de la narrabilidad: la identidad de los personajes ficticios a menudo resulta dudosa o múltiple, eso se tematiza también en la multiplicidad del arraigo cultural y lingüístico, y se manifiesta simbólicamente en las denominaciones, en la dualidad "propio-extraño". El estilo narrativo de Viktor Cholnoky es caracterizado por la división de la función narrativa entre varios narradores y por el incremento de la incertidumbre mediante la aparición de la postura narrativa desconfiable, ya que esta multiplica los momentos inciertos de la historia narrada. ${ }^{15}$ La narración es autorreflexiva, los textos se hacen modernos a través de alusiones metalépticas e irónicas, de imágenes que bordean lo grotesco, y también de moldes intertextuales, perdiendo así "casi todo de lo que es la historia, y, en ellos, no hay otra cosa que mantenga unido el mundo como una visión que las palabras cálidas, semejantes a almas" (Géczi, 1999: 218). ${ }^{16}$

En numerosos relatos de Viktor Cholnoky, un acontecimiento del mundo (ficticio) se disuelve en un juego lingüístico mediante el uso metafórico del lenguaje. A pesar de que Cholnoky represente también la narración anecdótica, ya que muchos de sus textos construidos hacia un remate final y tal vez tendiendo hacia lo fantástico- cuenten una "historia", el juego lingüístico elimina el carácter anecdótico con los motivos autorreflexivos que deconstruyen la historia, al convertirse la expresión metafórica en historia narrada. En el cuento titulado "Polixéna kisasszony pöre" [El pleito de la señorita Polixena], se observa un cambio de historia en distintos niveles, en el que la expresión figurada "caer fulminado" se convierte en realidad (ficticia) vivida y detalladamente narrada. Según el personaje que narra la historia de la vieja señorita pleiteante, ella es "obstinada, maligna y pertinaz [...], estaba reñido con todo el vecindario" y "era una plaga para todos" (Cholnoky, 1999: 36). El motivo de la "plaga" persiste a lo largo de la historia, en paralelismo con la aparición de la tormenta y de los truenos: "Llevaba una cartera de mano, urdida de mariposas de acero que tintinaba a cada movimiento. Afuera, mientras tanto, la tormenta iba cobrando fuerza, y los truenos se volvían más y más audibles" (1999: 38); y luego se fortalece el paralelismo entre figura y fenómeno natural: "Me sorprendí [...] pero la señorita Polixena, con gesto amplio, dio un puñetazo apasionado en el aire. En el mismo momento, afuera destelló un gran relámpago deslumbrante" (1999: 38).

La figura, que de esta forma se asocia gradualmente a la tormenta, acaba convirtiéndose en tormenta personificada, la cual termina quemada por el relámpago que ella misma produjo (según, al menos, la percepción subjetiva del narrador-personaje), identificándose con la imagen del cielo furioso:

\footnotetext{
${ }^{15}$ Un análisis detallado sobre los rasgos narrativos del modo de escribir de Cholnoky, en cuanto a un grupo de sus cuentos, se puede leer en Orosz, 2006.

${ }^{16}$ Véase también Sánta, Gábor: "Cholnoky Viktor Amanchich-novellái.” En: Géczi János (ed.): Cholnoky Viktor. Edición temática de Vár Ucca Tizenhét. Veszprém, 1993. 91-99.
} 
Entonces, la vieja señorita de ojos brillantes, labios contorcidos y arrugas serpenteadas explotó con toda su rabia. Afuera, el cielo restallaba, caían relámpagos uno tras el otro [...] y babeaba también la boca de Polixena cuando me gritó y dio un gran puñetazo sobre el escritorio de mi amo:

"Si no me lo dejáis, ¡que caigáis fulminados por la ira de Dios!"

En aquel momento, me ensordeció el ruido de algún ruido seco, no terrenal. [...] todo era llamas [...] En la marea de llamaradas, vi a la señorita Polixena que se quemaba. Vi como prendía fuego su vestido reluciente y su cuerpo [...] y en el delirio del desmayo principiante vi también que cada uno de los fragmentos de sus chispas se transformaban en deformes insectos miriópodos, y este enjambre pavoroso, en medio del furor de la tormenta, salía crepitando, hambriento y alegre a través de la ventana abierta [...] por el relámpago... (1999: 39sigs.)

La metáfora convertida en historia narra un acontecimiento fantástico, la metamorfosis de un ser humano que se queda dentro de los confines de la ambivalencia fantástica debido a la incertidumbre multiplicada por la función narrativa: en el relato, la terrible tormenta antropomorfizada y la imagen de la metamorfosis de Polixena se ven enmarcadas en una historia que prefigura la historia incrustada mediante el motivo de la tormenta. En el relato marco, el narrador primario da cuenta de cómo había escuchado la historia en un estado de conciencia peculiar, "algo como un dulce adormecer" (1999: 33), y luego, el narrador de la historia enmarcada se vuelve "desconfiable", ya que la situación extraordinaria y los fenómenos de la naturaleza lo despojan de su percepción: “[...] perdí mis sentidos, no de repente, sino poco a poco, sucesivamente, uno por uno, así me hundí en la noche llamada desmayo" (1999: 40).

Los relatos de los dos narradores desencadenan un juego de doble perspectiva, los dos subjetivados y desconfiables en sí: su conjunto aleja y pone en duda ulteriormente lo narrado. La historia narrada / por narrar pierde su función, se enajena y se separa de su realidad ficticia, el uso lúdico y metafórico del lenguaje cobra protagonismo, "la atribución de sentido se apoya en la metáfora" (Thomka, 2001: 22), sin embargo, se relaciona con la ambivalencia, característica de lo fantástico. Al mismo tiempo, la metáfora se ensancha hasta el nivel simbólico-mítico: la figura se convierte en el símbolo del furor, amalgamando en sí misma la imagen lingüística figurada a manera de una erinia o una furia. Manteniendo la posibilidad de una interpretación intertextual y mítica, el texto la enajena a la vez mediante un elemento de juego lingüístico: el nombre "Polixena", rimando con "filoxera", vuelve a poner las perspectivas metafóricas y míticas en una dimensión concreta, objetivada.

\subsection{Metamorfosis fantástica en el cuento de Leo Perutz}

Se observa un procedimiento y un motivo similares en "La fonda del Cartucho" ("Das Gasthaus zur Kartätsche”), cuento de Leo Perutz. Perutz, nacido en Praga, puede considerarse como representante de la literatura alemana en Praga, pero la vida adulta y el período de sus éxitos literarios lo relacionan con Viena. ${ }^{17}$ Sus obras (novelas y cuentos) tienen cierta característica peculiar: el discurso narrativo autorreflexivo y metaléptico, ${ }^{18}$ en el que se observan — con ciertas reservas - rasgos fantásticos, aunque a Perutz no se le pueda incluir

\footnotetext{
${ }^{17}$ A propósito de la categorización de Perutz en la historia literaria, véase Hollebrandt, Claudia: Das emotionale Wirkungspotenzial von Erzähltexten. Mit Fallstudien zu Kafka, Perutz und Werfel. Berlin: Akademie Verlag, 2011. Para el resumen de su vida y de su obra, consúltese Müller, 2007.

${ }^{18}$ A propósito de las peculiaridades narrativas de Perutz, véase Kindt, Tom / Meister, Jan-Christoph (eds.): Leo Perutz' Romane. Von der Struktur zur Bedeutung. Tübingen: Niemeyer, 2007.
} 
de manera unívoca en la literatura fantástica de la modernidad temprana, dado que la excede por sus propiedades narrativas. ${ }^{19}$

El cuento titulado "La fonda del Cartucho" ${ }^{20}$ narra la historia del sargento Chwastek, en cuya vida han acontecido "metamorfosis" particulares, tal como procura reconstruirlas Friseck, el yo-narrador, a través de memorias, manifestaciones y señales indirectas. ${ }^{21}$ Los momentos de la narración son simbólicos y metafóricos, punteados por elementos fantásticos, y urden una red espantosa y misteriosa. La imagen introductoria de la bala, con un recorrido casi humanamente extraño, prefigura la autonomización de los objetos -que amenazan al hombre en la primera guerra mundial prolépticamente mencionada-, y dibuja el perfil borroso de un mundo incomprensible. Aparecen también metamorfosis que apuntan hacia otras direcciones: la escena en la que el yo-narrador — debido al estado febril de su enfermedad incipiente - visiona la metamorfosis de los gastadores en insectos, evoca una imagen pavorosa, grotesca. En el contexto del relato, la perspectiva cambiante que implica la metamorfosis se ve determinada por el estado de conciencia del yo-narrador febril, cada vez más borracho: "Cuanto más bebía más me subía la fiebre y más fuertes eran los escalofríos. Pero yo no paraba, no qería ir a casa. [...] Las numerosas copas de aguardiente se me habían subido a la cabeza. Estaba muy cansado, me sentía mal [...]..$^{22}$

La percepción del yo-narrador semi-borracho, semi-enfermo conlleva a la metamorfosis de las figuras humanas en animales:

A través del humo de tabaco, a través de los vapores de la cerveza y del vino de la fonda, vi cómo unos monstruos grandes y torpes salían despacio y pesadamente de los rincones. Parecían insectos gigantescos, una maraña de cabecitas negras y piernas largas y flacas. Nos miraban con ojos verdes vidriosos y se acercaban cada vez más hacia nosotros. Grité aterrado sujetando el brazo del sargento.

Es como si el sargento Chwastek percibiera la visión del yo-narrador, que atribuye una interpretación simbólica y metafórica a lo visto: "Son mis recuerdos. [...] Esto sólo me concierne a mí. Son los días pasados". La interpretación incierta de lo visto persiste (tanto para el yo-narrador como para el lector), ya que está determinada por el estado de conciencia ambivalente del yo-narrador que lo percibe. ${ }^{23}$ El relato tematiza así el peligro al que está expuesto el sujeto autónomo, para el cual el mundo exterior se vuelve borroso e invisible detrás de su contorno aparentemente claro, y al mismo tiempo, la integridad del ser humano se ve amenazada también por su mundo interior, vivido como proyección de sus miedos visionarios.

Según afirma Martínez, Perutz representa la variante tradicional de lo fantástico, que

\footnotetext{
${ }^{19}$ En este respecto, Lüth habla de "un arte narrativa ambivalentemente fantástica" (1990: 49) y de sus "novelas histórico-fantásticas" (1990: 40).

${ }^{20}$ El cuento fue publicado en 1920, tal como lo aclara el editor en una nota en Perutz, Leo: Herr, erbarme Dich meiner! Viena: Zsolnay, 1995. 213.

${ }^{21}$ Para un análisis narratológico detallado del cuento véase Orosz, 2007.

${ }^{22}$ A falta de acceso a la edición impresa, todas las citas provienen de la edición digital incluida en la Bibliografía, sin señalar las páginas. (Nota del traductor)

${ }^{23}$ A la vez, la escena remite a El niño misterioso, obra de E.T.A. Hoffmann, en que la figura del Maestro Tinta sufre una metamorfosis análoga, o se percibe como insecto en metamorfosis constante. Hay otras referencias a Hoffmann en el texto, dado que Perutz consideró el modo de narrar autorreflexivo de Hoffmann como modelo importante. En cuanto a los elementos intertextuales de "La fonda del Cartucho", véase mi obra citada en la nota anterior.
} 
crea mundos heterogéneos e inestables (2002: 125), pero al mismo tiempo difiere de sus contemporáneos autores fantásticos (Kubin o Meyrink, entre otros), que interpretan lo fantástico de una manera ocultista, al ironizar constantemente sobre los elementos fantásticos y utilizarlos de una manera lúdica, tematizando el relato mismo (2002: 125), alcanzando de esta manera el efecto ambivalente que sirve de base a lo fantástico con varios procedimientos narrativos. ${ }^{24}$ Como resultado de la percepción ambivalente y la persistencia de la incertidumbre, en cambio, el texto conserva los rasgos de lo fantástico "clásico", empujándolos también hacia una interpretación metafórica.

\subsection{Metamorfosis fantástica: la metamorfosis de lo fantástico en Kafka}

La escena de la metamorfosis en el texto de Perutz se parece a otra metamorfosis que nos conduce hacia una nueva calidad de lo fantástico. La metamorfosis de Franz Kafka también desarrolla el motivo de la transformación en insecto, pero en Kafka, este se manifiesta de forma mucho más detallada y funciona como elemento estructural. La intertextualidad entre el texto de Perutz y de Kafka es solo diferida: aunque el relato de Kafka se editó en 1915, y "La fonda del Cartucho", en 1920, Perutz había publicado la primera versión del cuento bajo el título Der Feldwebel Schramek [El sargento Schramek] en 1907, mucho antes que Kafka, en la que también incluye la misma escena (algo reducida). ${ }^{25}$

El relato de Kafka comienza de manera insólita, ya que la primera frase expone el estado cambiado del protagonista, la metamorfosis, y basa todo el universo narrado heterogéneo (fundado en las premisas compatibles e incompatibles de su realidad) en este acontecimiento inicial:

Cuando, tras unos sueños intranquilos, Gregorio Samsa se despertó esa mañana, se encontró convertido en un enorme insecto. Yacía sobre el duro caparazón y si levantaba un poco la cabeza, veía su vientre oscuro, abombado, dividido a trechos por refuerzos en forma de arco, en cuyas prominencias la colcha apenas podía sostenerse, pues a punto parecía de resbalar por completo. Sus numerosas patas, ridículamente delgadas en comparación con el volumen anterior de sus piernas, se agitaban desvalidas ante sus ojos. (2002: 29)

Con la excepción de la metamorfosis, no hay ningún cambio en el mundo narrado. Gregorio Samsa está circundado por el mismo mundo burgués, y en su caso también podemos excluir el cambio del estado de conciencia, puesto que — según subraya la frase inicial— acaba de despertarse de su "sueño intranquilo", y por tanto, ha abandonado el estado que facilitaría la percepción fantástica y ambivalente, y ha vuelto al estado vigilante: “—¿Qué es lo que me ha ocurrido? - pensó. / No se trataba de un sueño. Su habitación, una habitación humana corriente, quizás sólo excesivamente pequeña, aparecía, como de ordinario, entre sus cuatro familiares paredes" (2002: 29). La metamorfosis trastorna las dimensiones y dificulta la percepción y el movimiento: "Pero las dificultades vinieron después, principalmente a causa de la extraordinaria anchura de su cuerpo. Para incorporarse habría necesitado brazos y manos, pero en su lugar disponía solamente de innumerables patitas que ejecutaban sin cesar los más variados movimientos y que, además, no podía dominar” (2002: 33sigs.).

\footnotetext{
${ }^{24}$ Jacquelin resalta esta misma propiedad (2002: 35).

${ }^{25}$ Para el análisis de la primera variante véase Müller, 2007: 44sigs. Para la comparación de las dos variantes, consúltese Orosz, 2007: 1sigs.
} 
Sin embargo, el personaje metamorfoseado en insecto y las demás figuras (su familia) acogen este acontecimiento "inaudito" como evidencia, que sí embarga su vida cotidiana - y acaba imposibilitándola en el caso de Gregorio-, pero no evoca el sentimiento ambivalente de terror o de miedo, omnipresente en los textos fantásticos; eso es, según afirma Martínez, en este caso, al contrario de lo fantástico tradicional, se establece un mundo heterogéneo pero estable (2002: 125). Nix opina que los segmentos del universo narrado heterogéneo se funden de alguna forma, dando un resultado paradójico y resaltando el peculiar procedimiento metafórico (2005: 110sig.). En este caso son precisamente el sinsentido de la vida del hombre - convertido en insecto - y la absurdidad del mundo inclinado a lo grotesco - con frecuente tendencia hacia lo absurdo en Kafka-, aspectos que se pueden interpretar como metáfora originada del procedimiento neo-fantástico. Así nace, con Kafka, una nueva forma de lo fantástico, que más tarde se hace variante factible de la creación moderna a base de la "herencia" kafkiana en autores como Jorge Luis Borges, Julio Cortázar y Gabriel García Márquez.

\subsection{Metamorfosis invertida: confirmación neo-fantástica}

La utilidad y la continuidad del modelo kafkiano quedan demostradas en "Gregor", cuento corto de Quim Monzó, ${ }^{26}$ propuesta intertextual de La metamorfosis, que invierte la transformación kafkiana, ya que es el insecto el que se convierte en ser humano:

Cuando, una mañana, el escarabajo salió del estado ninfal se encontró convertido en un chico gordo. Yacía sobre la espalda sorprendentemente blanca y desproporcionada y, si levantaba un poco la cabeza, se veía la verruga, pálida e inflada. El número de extremidades se había reducido de manera drástica y las pocas que sentía (cuatro, contaría más tarde) eran dolorosamente carnosas, y tan gruesas y pesadas que moverlas le resultaba imposible. (2004: 26)

A continuación, se repite casi literalmente la estupefacción del Gregor kafkiano sobre su nuevo estado: “¿Qué le había pasado? Ahora, la habitación le parecía pequeñísima, y menos intenso el olor de moho que percibía antes" (2004: 26). Las dimensiones se invierten en su opuesto con el cambio a la figura humana: "Qué pequeñas les parecían ahora todas aquellas cosas que, antes, apenas podía abarcar en su totalidad" (2004: 26), y también se repite la tortura causada por los cambios de posición, con la premisa opuesta: "Fuerza tenía, pero era evidente que no sabía cómo dominarla y que cada uno de sus movimientos eran descoyuntados e inconexos, sin relación con los demás. Cuando aprendiese a usar las extremidades, las cosas mejorarían tan notablemente que podría irse con los suyos" (2004: 27).

Esta transformación física —al igual que en Kafka - no suscita terror ni miedo: el insecto que se ha vuelto humano va adaptándose a su nueva percepción y a sus nuevas circunstancias, tal como sucede en el mundo kafkiano. Sin embargo, a consecuencia de la metamorfosis, el personaje de Monzó acaba por alejarse de su familia, invirtiendo la manera en que la familia — en Kafka — se aleja cada vez más de Samsa, ya que este llega a pesarles, y se deshacen de él en cuanto deja su existencia de insecto y se convierte en desecho.

\footnotetext{
${ }^{26}$ Quisiera aprovechar la ocasión para agradecer a Ádám Kürthy por haberme llamado la atención sobre el texto de Monzó.
} 
El insecto convertido en humano liquida los miembros de su familia de antaño que le recuerdan su mundo anterior: "[...] fue al cuarto y, mientras descolgaba la fregona, vio, arrimados a la pared, tres escarabajos que, después de un instante de inmovilidad, intentaron huir. Con un cierto asco les puso encima el pie derecho e hizo presión hasta que notó como se chafaban" (2004: 31). Se establece una referencia intertextual sistemáticamente invertida, que al mismo tiempo consolida el modelo neo-fantástico: Monzó remite lúdicamente a las primeras fuentes de lo neo-fantástico y, manteniendo el mecanismo de su propio relato (y de los textos neo-fantásticos en general), llega hasta una reflexión algo irónica.

\section{Mutaciones: la persistencia de lo fantástico}

Los cuatro textos mencionados representan distintas vertientes de lo fantástico: Cholnoky y Perutz siguen la estructura de lo fantástico "tradicional", pero presuponen su transición metafórica: la historia narrada supera su carácter fantástico y señala su propio carácter lingüístico y retórico. El cuento de Kafka documenta el nacimiento de lo neo-fantástico, mientras que Monzó invierte la historia kafkiana siguiendo el mismo molde.

Sin embargo, la referencia intertextual es un rasgo común en los cuatro textos, todos varían el modelo antiguo de la "metamorfosis" en sentido amplio, y su mundo textual incluye ulteriores motivos intertextuales: el cuento de Cholnoky complementa la metamorfosis con la escala de moldes antiguos con una mención lúdica a la diosa de la discordia. Perutz pone en juego lo fantástico clásico con su alusión intertextual a Hoffmann: él mismo resaltó su propia inclinación afirmando que "siempre ha dejado la puerta entreabierta [...] ante el universo de E.T.A. Hoffmann" (citado por Cothran, 1990: 36), ${ }^{27}$ y así establece un parentesco literario con un autor cuyos textos entretejidos de elementos fantásticos han creado una red de interrelaciones textuales y unos modelos persistentes. ${ }^{28} \mathrm{La}$ consonancia fortuita entre las metamorfosis de Perutz y de Kafka — más allá del mero contacto- revela la diferencia fundamental entre las dos maneras de la construcción fantástica del texto, y resalta a Kafka como renovador de lo fantástico clásico (Nix, 2005: 109). La historia kafkiana aparentemente no sigue moldes intertextuales, alude, sin embargo, inmediatamente en su título, a la tradición intertextual de la transformación y la metamorfosis que reaparece en el texto de Monzó, relacionándolo con la continuación intertextual de Kafka, evidente ya desde su título.

La puesta en escena de la posibilidad de la transición entre la esfera humana y aquella animal es un rasgo común de los cuatro textos que señala la amenaza y el desamparo del ser humano ante las fuerzas exteriores e interiores, poniendo de relieve la incertidumbre de la percepción con una fuerza metafórica evocadora; reflexionando a la vez sobre la textualidad del relato en su discurso narrativo. Mientras que Cholnoky y Perutz tematizan el terror en relación con la metamorfosis, Kafka y Monzó presentan la metamorfosis como fenómeno del universo narrado: metáfora (del proceso) de la deshumanización.

\section{Traducción de Ádám András Kürthy}

\footnotetext{
${ }^{27}$ La afinidad de Perutz hacia Hoffmann también se menciona en Jacquelin, 2002: 22.

${ }^{28}$ Para ello, véase Orosz, Magdolna: Identität, Differenz, Ambivalenz. Erzählstrukturen und Erzählstrategien bei E.T.A. Hoffmann. Frankfurt a.M.: Peter Lang 2001, 157-198, 224sigs.
} 


\section{Bibliografía}

ALAZRAKI, Jaime: “¿Qué es lo neofantástico?”. Mester 19/2 (1990): 21-33.

BARBETTA, María Cecilia (2006): "Wie die phantastische Hand neo-phantastisch wird. Eine Einführung in die Poetik des Neo-Phantastischen". Nach Todorov. Beiträge zu einer Definition des Phantastischen in der Literatur. Eds. Clemens Ruthner, Ursula Reber y Markus May. Tübingen, Francke: 209-225.

CAILLOIS, Roger (1965): Au coeur du fantastique. París, Gallimard.

CERSOWSKY, Peter (1983): Phantastische Literatur im ersten Viertel des 20. Jahrhunderts. Untersuchungen zum Strukturwandel des Genres, seinen geistesgeschichtlichen Voraussetzungen und zur Tradition der ,schwarzen Romantik” insbesondere bei Gustav Meyrink, Alfred Kubin und Franz Kafka. München, Wilhelm Fink.

CHOLNOKY Viktor (1999): “Polixéna kisasszony pöre”. Wurmdrucker Tóbiás és egyéb kisértések. Budapest, Ister: 32-41.

COTHRAN, Bettina F.: "Der «Einbruch der E.T.A. Hoffmannschen Welt» in den Werken von Leo Perutz”. Mitteilungen der E.T.A. Hoffmann. Gesellschaft 36 (1990): 36-47.

DURST, Uwe (2001): Theorie der phantastischen Literatur. Tübingen/Basel, Francke.

GÉCZI János (1999): “A kék szemü Cholnokyak”. Cholnoky Viktor: Wurmdrucker Tóbiás és egyéb kísértések. Budapest, Ister: 209-218.

INNERHOFER, Roland (1996): Deutsche Science Fiction 1870-1914. Rekonstruktion und Analyse der Anfänge einer Gattung. Wien/Köln/Weimar, Böhlau. DOI: https://doi.org/10.7767/9783205123279

JACQUELIN, Evelyne (2002): "Théories et lectures du fantastique d'un bord à l'autre du Rhin: L'exemple de Leo Perutz". Merveilleux et fantastique dans les littératures centreeuropéennes. Eds. Bernard Banun y Delphine Bechtel. París, Centre Interdisciplinaire de Recherches Centre-Européennes / Université de Paris-Sorbonne: 21-38.

KAFKA, Franz (2002): La Metamorfosis. Trad. sin señalar. Madrid, Editorial Alba.

LÜTH, Reinhard: "Leo Perutz und das Fin-de-Siècle. Zu den literarischen Anfängen des Romanautors Leo Perutz und ihren Wurzeln in der Wiener Literatur um 1900". Modern Austrian Literature 23/1 (1990): 35-53.

MARTÍNEZ, Matias (2002): "Proleptische Rätselromane. Erzählrahmen und Leserlenkung bei Leo Perutz". Leo Perutz. Unruhige Träume - Abgründige Konstruktionen. Dimensionen des Werks, Stationen der Wirkung. Eds. Brigitte Forster y Hans-Halard Müller. Viena, Sonderzahl: 107-129.

MONZÓ, Quim (2004): “Gregor”. Quim Monzó. Sel. Víctor Cabrera. México, Universidad Nacional Autónoma de México: 26-31.

MUSIL, Robert (1977): A tulajdonságok nélküli ember. Trad. Dezső Tandori. Budapest, Európa.

MÜLLER, Hans-Harald (2007): Leo Perutz. Biographie. Viena, Zsolnay.

NIX, Daniel (2005): Kafka als phantastischer Erzähler? (Neo-)Phantastische Elemente und Realitätssysteme in den Texten Franz Kafkas. Wetzlar, Förderkreis Phantastik in Wetzlar. 
OROSZ, Magdolna (2006): “Utazás kultúrák között. Interkulturális mozzanatok Cholnoky Viktor Trivulzió-novelláiban." Induló modernség - kezdődö avantgárd. Eds. Gábor Bednanics y György Eisemann. Budapest, Ráció: 102-122.

--- (2007): "Identität, Identitätskonstruktion und Phantastik bei Leo Perutz". Kakanien Revisited, el 24 de octubre de 2007. Disponible en: http://www.kakanienrevisited.at/beitr/emerg/morosz2.pdf (última consulta: 27/10/2017).

PERUTZ, Leo: "La fonda del Cartucho". ;Señor, apiadate de mi!!. Edición digital disponible en: http://bdigital.reduniv.edu.cu/epubreader.php?data $=2449 \& \mathrm{db}=5 \quad$ (última consulta: 27/10/2017).

TITZMANN, Michael (1989): "Das Konzept der «Person» und ihrer «Identität» in der deutschen Literatur um 1900". Die Modernisierung des Ich. Studien zur Subjektkonstitution in der Vor- und Frühmoderne. Ed. Manfred Pfister. Passau, Wissenschaftsverlag Richard Rothe: 36-52.

THOMKA Beáta (2001): Beszél egy hang. Elbeszélők, poétikák. Budapest, Kijárat Kiadó.

TITZMANN, Michael: "Das «Unsichtbare» und die Phantasie der «Macht». Verknüpfungen von Okkultismus und Wissenschaft in der Frühen Moderne". Sciences, sciences occultes et littérature (1890-1935). Textos reunidos por Christine Maillard. Recherches Germaniques. Revue annuelle 1 (2002): 173-202.

TODOROV, Tzvetan (1981): Introducción a la literatura fantástica. $2^{\mathrm{a}}$ ed. México: Premia. Edición digital: http://iesliteratura.ftp.catedu.es/lectura/cuarto_atras/imagenes/Todorov.pdf (última consulta: 27/10/2017).

VAX, Louis (1960): L'art et la littérature fantastiques. París, Presses Universitaires de France.

--- (1992): “Thèses sur le fantastique”. E.T.A. Hoffmann et le fantastique. Ed. Jean-Marie Paul. Nancy, Centre de Recherches Germaniques et Scandinaves de 1'Université de Nancy: 742.

WÜNSCH, Marianne (1989): “Wege der «Person» und ihrer «Selbstfindung» in der fantastischen Literatur nach 1900". Die Modernisierung des Ich. Studien zur Subjektkonstitution in der Vor- und Frühmoderne. Ed. Manfred Pfister. Passau, Rothe: 168179.

--- (2000): "Phantastik in der Literatur der frühen Moderne". Naturalismus, Fin de Siècle, Expressionismus 1890-1918. Ed. Mix York-Gothard. (Hansers Sozialgeschichte der deutschen Literatur vom 16. Jahrhundert bis zur Gegenwart, 7.) München, Hanser: 175-191.

(C) Magdolna Orosz

(C) Ádám András Kürthy

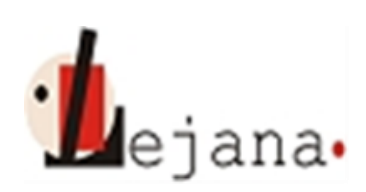

http://ojs.elte.hu/index.php/lejana

Universidad Eötvös Loránd, Departamento de Español, 1088 Budapest, Múzeum krt. 4/C 